La estética de la radio se ha ido modificando a lo largo de la historia, pero conservó ejes transversales básicos

Juan José Montero

Question/Cuestión, Vol. 2, N 66, Agosto 2020

ISSN 1669-6581

https://perio.unlp.edu.ar/ojs/index.php/question/index

IICom-FPyCS-UNLP

\section{“LA ESTÉTICA DE LA RADIO SE HA IDO MODIFICANDO A LO LARGO DE LA HISTORIA, PERO COSERVÓ EJES TRANSVERSALES BÁSICOS"}

\author{
“THE RADIO AESTHETICS HAS BEEN MODIFIELD THROUGHOUT \\ HISTORY, BUT RETAINED BASIC TRANSVERSAL AXES"
}

Juan José Montero

Operador técnico de estudios de radio y TV Posgrado Gestión de industrias culturales. Universidad Nacional de Tres de Febrero. Especialización en industrias culturales en la convergencia digital. UNTREF juanjomonteropaz@gmail.com IG: @rokablonda Twitter: @rokablonda 


\section{Resumen}

El Operador de Sonido, Juan José Montero, recorre históricamente la creatividad, producción y realización de las propuestas estéticas radiales. Desde la edición en vivo a la edición digital.

\section{Palabras clave}

Radio, Estética, Sonidos, Producción, Edición en vivo, Compaginación, Edición Digital

\section{Abstract}

The Sound Operator, Juan José Montero, makes a historical journey through the creativity, production and realization of radio aesthetic proposals. From live to digital edition.

\section{Keywords}

Radio, Aesthetics, Sounds, Production, Live Edition, Layout, Digital Edition

\section{Enlace}

https://go.ivoox.com/rf/55560164 